\title{
THE LAVES PHASE EMBRITTLEMENT OF FERRITIC STAINLESS STEEL TYPE AISI 441
}

Maitse P. Sello 


\title{
THE LAVES PHASE EMBRITTLEMENT OF FERRITIC STAINLESS STEEL TYPE AISI 441
}

\author{
BY \\ Maitse P. Sello

\section{SUPERVISED BY Professor Waldo E. Stumpf}

Submitted in fulfilment of the requirements for the degree Philosophiae Doctor, PhD (Metallurgy)

in the

Department of Materials Science and Metallurgical Engineering

Faculty of Engineering, Building Environment and Information Technology

University of Pretoria

Republic of South Africa

2009, June 15

(C) University of Pretoria 
PREFACE

This dissertation is submitted for the degree of Doctor of Philosophy at the University of Pretoria. The research described herein was conducted under the supervision of Professor W. Stumpf in the department of Materials Science and Metallurgical Engineering, University of Pretoria.

Except where acknowledgements and references are made to previous work, this work is, to the best of my knowledge, original. This dissertation is the result of my own work and includes nothing of which is the outcome of work done in collaboration with others except where specifically indicated in the text. Neither this, nor any substantially similar dissertation has been, or is being submitted to my knowledge for any other degree, diploma, or other qualification at any other university.

Maitse P. Sello 


\section{ACKNOWLEDGEMENT}

I would like to thank God for his guidance in my life, and also for being my strength and guidance in my life.

I would like to express my sincere thanks to my academic supervisor, Prof. Waldo E. Stumpf for his invaluable guidance, encouragement and input in this research project. I have benefited a lot from his experience and insight during this research project.

I would like to thank Mrs Sarah Havenga, Mrs Lillian Barlow and Mrs Elsie Snyman Ferreira for their help with the administrative work.

I would like to thank Prof L. Cornish (currently at the University of Witswatersrand) and Mrs L. H. Chown for their training and guidance during thermodynamic modelling using Thermo-Calc® software at Mintek

I would like to thank Mrs A. Tuling and Mr C. van der Merwe for their help with TEM work, Dr N. van der Berg for his expertise in the electron diffraction indexing and Mr C. Coetzee for his help with the SEM.

I would also like to thank Dr S. Verryne and Prof. J de Villiers for their help in XRD analysis and also their expertise, they have always been available for help whenever needed, and for that I am very grateful.

I would like to thank everyone at the University for company and support during my time there. There are many interesting, encouraging and happy moments to remember with my friends during the course of my studies.

Finally I would like to thank my parents and siblings for supporting me in every decision that I have taken in my life, thank you for your support and patience. 


\title{
THE LAVES PHASE EMBRITTLEMENT OF FERRITIC STAINLESS STEEL \\ TYPE AISI 441
}

\section{Author: $\quad$ Maitse P. Sello}

\author{
Supervisor: Professor Waldo E. Stumpf
}

Department of Materials Science and Metallurgical Engineering

University of Pretoria

Philosophiae Doctor (Materials Science and Metallurgical Engineering )

\section{Synopsis}

The effect of Laves phase $\left(\mathrm{Fe}_{2} \mathrm{Nb}\right)$ formation on the Charpy impact toughness of the ferritic stainless steel type AISI 441 was investigated. The steel exhibits good toughness after solution treatment at $850{ }^{\circ} \mathrm{C}$, but above and below this treatment temperature the impact toughness decreases sharply. With heat treatment below 850 ${ }^{\circ} \mathrm{C}$ the presence of the Laves phase on grain boundaries and dislocations plays a significant role in embrittlement of the steel whereas above that temperature, an increase in the grain size from grain growth plays a major role in the impact embrittlement of this alloy. The toughness results agree with the phase equilibrium calculations made using Thermo-Calc $®$ whereby it was observed that a decrease in the Laves phase volume fraction with increasing temperature corresponds to an increase in the impact toughness of the steel. Annealing above $900{ }^{\circ} \mathrm{C}$ where no Laves phase exists, grain growth is found which similarly has a very negative influence on the steel's impact properties. Where both a large grain size as well as Laves phase is present, it appears that the grain size may be the dominant embrittlement mechanism. Both the Laves phase and grain growth, therefore, have a significant influence on the impact properties of the steel, while the Laves phase's precipitation behaviour has also been investigated with reference to the plant's manufacturing process, particularly the cooling rate after a solution treatment.

The microstructural analysis of the grain size shows that there is a steady increase in grain size up to about $950{ }^{\circ} \mathrm{C}$, but between $950{ }^{\circ} \mathrm{C}$ and $1000{ }^{\circ} \mathrm{C}$ there is a sudden and rapid $60 \%$ increase in the grain size. The TEM analysis of the sample that was annealed at $900{ }^{\circ} \mathrm{C}$ shows that the Laves phase had already completely dissolved and cannot, therefore, be responsible for "unpinning of grain boundaries" at temperatures of $900{ }^{\circ} \mathrm{C}$ and higher where this "sudden" increase in grain size was found. The most 
plausible explanation appears to be one of $\mathrm{Nb}$ solute drag that loses its effectiveness within this temperature range, but this probably requires some further study to fully prove this effect.

During isothermal annealing within the temperature range of 600 to $850{ }^{\circ} \mathrm{C}$, the time temperature - precipitation (TTP) diagram for the Laves phase as determined from the transformation kinetic curves, shows two classical $\mathrm{C}$ noses on the transformation curves. The first one occurring at the higher temperatures of about 750 to $825{ }^{\circ} \mathrm{C}$ and the second one at much lower temperatures, estimated to possibly be in the range of about 650 to $675^{\circ} \mathrm{C}$. The transmission electron microscopy (TEM) analyses show that there are two independent nucleation mechanisms that are occurring within these two temperature ranges. At lower temperatures of about $600{ }^{\circ} \mathrm{C}$, the pertaining nucleation mechanism is on dislocations and as the temperature is increased to above $750{ }^{\circ} \mathrm{C}$, grain boundary nucleation becomes more dominant. Also, the morphology of the particles and the misorientation with the matrix changes with temperature. At lower temperatures the particles are more needle-like in shape, but as the temperature is increased the shape becomes more spheroidal.

The effect of the steel's composition on the Laves phase transformation kinetics shows that by lowering the $\mathrm{Nb}$ content in these type 441 stainless steels, had no significance effect on the kinetics on precipitation of the Laves phase. However, a Mo addition and a larger grain size of the steel, retard the formation of the Laves phase, although the optimum values of both parameters still need further quantification.

The calculation made for the transformation kinetics of the Laves phase, using the number density of nucleation sites $N_{0}$ and the interfacial energy $\gamma$ as the fitting parameters in this work, demonstrated a reasonable agreement with experimental results.

Keywords: Laves phase $\left(\mathrm{Fe}_{2} \mathrm{Nb}\right)$, titanium niobium carbonitrides $(\mathrm{Ti}, \mathrm{Nb})(\mathrm{C}, \mathrm{N})$, impact embrittlement, grain size, ductile-to brittle transition temperature (DBTT), Laves phase transformation kinetics, Cottrell approach to grain size, Smith model of brittle grain boundary phases, Thermo- Calc®. 


\section{TABLE OF CONTENT}

Preface

ACKNOWLEDGEMENT

TABLE OF CONTENT

TABLE OF FIGURES

XIII

NOMENCLATURE

XIX

Chapter ONE

GENERAL INTRODUCTION

1.1 Introduction

1.2 Problem Statement 3

1.3 Objectives 3

$\begin{array}{ll}\text { Chapter Two } & 5\end{array}$

$\begin{array}{lc}\text { LITERATURE REVIEW } & 5\end{array}$

$\begin{array}{lll}2.1 & \text { Introduction } & 5\end{array}$

2.2 Classification of Stainless Steels $\quad 5$

2.2.1 Ferritic Stainless Steel 7

2.2.2 Austenitic Stainless Steel 7

2.2.3 Martensitic Stainless Steel 7

2.2.4 Duplex Stainless Steel 8

2.3 Composition of Stainless Steels $\quad 8$

2.3.1 Structure of Ferritic Stainless Steel 8

$\begin{array}{lll}2.4 & \text { Toughness of Ferritic Stainless Steels } & 10\end{array}$

2.4.1 Effect of Grain Size on Brittle Behaviour 10

2.4.2 Embrittlement at $475^{\circ} \mathrm{C} \quad 12$

2.4.3 Precipitation of the Secondary Phases in Stainless Steels 13

2.4.4 Notch Sensitivity 14

2.4.5 Weldability of Ferritic Stainless Steel $\quad 15$

2.4.6 Effect of Niobium and Titanium Additions to Ferritic Stainless Steels 15

$\begin{array}{lll}2.5 & \text { Theories of Brittle Fracture } & 16\end{array}$

2.5.1 Zener's/Stroh's Theory 17

2.5.2 Cottrell's Theory 18

2.5.3 Smith's Theory 21

2.5.4 Cleavage Fracture Resistance 23

$\begin{array}{lll}2.6 & \text { Thermomechanical Processing } & 23\end{array}$ 
2.6.1 Cold-Rolling

2.6.2 Hot-Rolling

2.6.3 Cooling Rate

2.6.4 Heat Treatment

2.7 Applications of Stainless Steels in Automobile Exhaust System 25

2.8 Heat Resistant Ferritic Stainless Steels 27

2.9 Stabilisation $\quad 27$

2.9.1 Stabilisation with Titanium 28

2.9.2 Stabilisation with Niobium $\quad 28$

2.9.3 Solid Solution Hardening and Solute Drag by Niobium 29

2.9.4 Effects of Temperature on Solute Drag 31

2.9.5 Dual Stabilisation with Titanium and Niobium 31

2.10 AISI Type 441 Stainless Steels 32

2.11 Calphad Methods 33

2.11.1 Thermodynamic Softwares

2.12 Intermetallic Laves Phase 36

2.12.1 Crystallographic Structure 36

$\begin{array}{lll}2.12 .2 & \text { Occurrence } & 37\end{array}$

2.12.3 Orientation Relationship 38

$\begin{array}{ll}\text { ChAPTER THREe } & 39\end{array}$

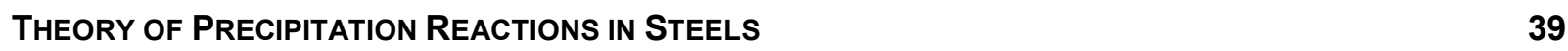

3.1 Introduction $\quad 39$

3.2 Classical Theory of Nucleation 39

3.2.1 Activation Energy for Nucleation within the Matrix 40

3.2.2 Activation Energy for Nucleation on the Grain Boundary 40

3.2.3 Misfit Strain Energy Around the Particle 42

3.2.4 Interfacial Energy 43

3.2.4.1 Fully Coherent Precipitates $\quad 44$

3.2.4.2 Incoherent Precipitates $\quad 45$

3.2.4.3 Semi-Coherent Precipitates 46

3.2.5 Nucleation Rate $\quad 46$

3.2.6 The Time-Dependent Nucleation Rate $\quad 47$

$\begin{array}{lll}\text { 3.2.7 Chemical Driving Force } & 48\end{array}$

$\begin{array}{lll}3.3 & \text { Growth by Supersaturation } & 49\end{array}$

3.3.1 Diffusion Controlled Growth Rate 50

3.3.2 Multicomponent Diffusion Growth

3.4 Transformation Kinetics $\quad 54$

3.5 Overall Transformation Kinetics $\quad 55$

3.5.1 The Robson and Bhadeshia Model 55

3.5.2 Fujita And Bhadeshia Model 56 
3.7 Dissolution of the Metastable Phase $\quad 58$

$\begin{array}{lll}3.8 & \text { Particle Coarsening } & 58\end{array}$

3.8.1 Diffusion Controlled Coarsening of the Particles within Matrix 58

3.8.2 Diffusion Controlled Coarsening of the Particles on Grain Boundary 59

3.8.3 Diffusion Controlled Coarsening of the Particles on Subgrain Boundaries 60

$\begin{array}{lll}3.9 & \text { Summary } & 60\end{array}$

$\begin{array}{lr}\text { CHAPTER FOUR } & 62\end{array}$

$\begin{array}{ll}\text { EXPERIMENTAL Procedures } & 62\end{array}$

$\begin{array}{lll}4.1 & \text { Materials } & 62\end{array}$

4.2 Thermodynamic Modelling $\quad 64$

4.3 Heat Treatments $\quad 64$

4.3.1 Laves Phase Dissolution/Precipitation Temperatures 64

4.3.2 Heat Treatment for the Embrittling Effect 64

4.3.3 Hot-Rolling of Experimental Alloys $\quad 66$

4.3.4 Laves phase Kinetic Study $\quad 66$

$\begin{array}{lll}4.4 & \text { Mechanical Testing } & 67\end{array}$

$\begin{array}{lll}\text { 4.4.1 } & \text { Tensile Tests } & 67\end{array}$

$\begin{array}{lll}\text { 4.4.2 Notched Charpy Impact Test } & 68\end{array}$

$\begin{array}{lll}\text { 4.4.3 Hardness Tests } & 68\end{array}$

$\begin{array}{lll}4.5 & \text { Microanalysis of Specimens } & 68\end{array}$

$\begin{array}{lll}\text { 4.5.1 Optical Microscopy } & 69\end{array}$

4.5.2 Transmission Electron Microscopy (TEM) 69

4.5.2.1 Preparation of TEM Specimens $\quad 69$

4.5.3 Scanning Electron Microscopy (SEM) $\quad 70$

$\begin{array}{lll}4.6 & \text { Identification of Precipitates } & 70\end{array}$

$\begin{array}{lll}\text { 4.6.1 XRD Study } & 70\end{array}$

4.6.1.1 Specimen Preparation $\quad 70$

$\begin{array}{lll}\text { 4.6.1.2 Analysis } & 71\end{array}$

$\begin{array}{lll}\text { 4.6.2 Electron Diffraction Patterns } & 76\end{array}$

4.7 The Orientation Relationship Between the Laves Phase and the Matrix 77

$\begin{array}{ll}\text { Chapter Five } & 78\end{array}$

$\begin{array}{ll}\text { THERMODYNAMIC MODELLING } & 78\end{array}$

$\begin{array}{lll}5.1 & \text { Introduction } & 78\end{array}$

$\begin{array}{lll}5.2 & \text { Description of Thermo-Calc } ® \text { Software } & 78\end{array}$

$\begin{array}{lll}5.3 & \text { Experimental Alloys } & 79\end{array}$

$\begin{array}{lll}5.4 & \text { Possible Stable Phases at Equilibrium } & 81\end{array}$

5.5 Phase Diagrams $\quad 82$ 
5.7 Relative Phase Stabilities $\quad 84$

5.8 Equilibrium Chemical Composition of the Laves Phase 89

$\begin{array}{lll}5.9 & \text { Driving Force for Nucleation } & 94\end{array}$

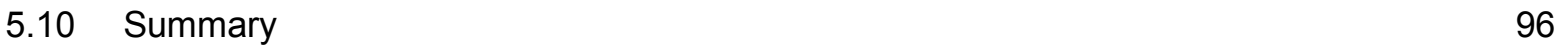

$\begin{array}{lr}\text { ChAPTER SiX } & 100\end{array}$

$\begin{array}{lr}\text { EXPERIMENTAL RESULTS } & 100\end{array}$

$\begin{array}{lll}6.1 & \text { Introduction } & 100\end{array}$

6.2 Microstructural Analysis of an AISI Type 441 Ferritic Stainless Steel 100

6.2.1 Precipitate's Identification 101

6.3 Effect of Annealing Treatment on the Microstructural and Mechanical Properties 107

$\begin{array}{lll}\text { 6.3.1 Microstructural Analysis } & 107\end{array}$

$\begin{array}{ll}\text { 6.3.2 Precipitate's Morphology } & 112\end{array}$

6.3.3 Mechanical Properties 113

6.3.4 Effect of Grain Size on the Mechanical Properties of Steel A 116

6.4 Effect of Annealing Treatment on the Charpy Impact Energy and DBTT 118

6.5 Effect of Re-embrittlement treatment on The Room Temperature Charpy Impact Energy 119

$\begin{array}{ll}\text { 6.5.1 Effect Of Cooling Rate } & 119\end{array}$

6.5.2 Effect of the Reheating Treatment 122

$\begin{array}{ll}\text { Chapter SeVen } & 125\end{array}$

$\begin{array}{lr}\text { EXPERIMENTAL RESULTS } & 125\end{array}$

$\begin{array}{lr}\text { Effect Of the Steel’s Composition } & 125\end{array}$

$\begin{array}{lll}7.1 & \text { Effect of Annealing Treatment on Steel B } & 125\end{array}$

7.2 Effect of the Equilibrium Laves Phase Volume Fraction on the Room Temperature Charpy Impact Energy

7.3 Effect of Annealing Treatment on the Embrittlement of the Experimental Stainless $\begin{array}{ll}\text { Steels } C \text { to } E & 128\end{array}$

$\begin{array}{lr}\text { Chapter Eight } & 131\end{array}$

$\begin{array}{ll}\text { EXPERIMENTAL RESULTS } & 131\end{array}$

$\begin{array}{ll}\text { Laves Phase Kinetics Study } & 131\end{array}$

$\begin{array}{lll}8.1 & \text { Introduction } & 131\end{array}$

$\begin{array}{ll}\text { 8.2 Equilibrium Laves Phase Fraction } & 131\end{array}$

8.3 Laves Phase Transformation Kinetics 133

8.4 Temperature Effect on Isothermal Transformations 134 
8.5 Effect of the Grain Size on the Transformation Kinetics of Laves Phase 135

8.6 Effect of the Steel's Composition on the Laves Phase's Transformation Kinetics 136

8.7 Microstructural Analysis of the Transformation Kinetics 137

8.8 Orientation Relationship Between the Laves Phase and the Ferrite Matrix 141

$\begin{array}{lr}\text { ChAPTER NINE } & 144\end{array}$

$\begin{array}{ll}\text { Discussions } & 144\end{array}$

LaVes Phase Embrittlement 144

$\begin{array}{lll}9.1 & \text { Introduction } & 144\end{array}$

9.2 Precipitates Found in AISI 441 Ferritic Stainless Steel 144

9.2.1 Effect of the Steel's Composition on the Precipitate's Solvus Temperature 145

9.2.2 Effect of the Steel's Composition on the Precipitate's Composition 147

9.3 Embrittlement of Type 441 Ferritic Stainless Steel 148

9.3.1 Effect of Grain Size on Flow Stress: the Hall-Petch Relationship 148

9.3.2 Crack Nucleation 149

9.3.3 Effect of Precipitates in the Embrittlement of this Steel 151

9.3.3.1 Embrittlement and the Cottrell's Approach 151

9.3.3.2 Embrittlement by Grain Boundary Precipitates (The Smith's Model) 154

9.3.3.3 Effect of Cooling Rate 157

9.4 Recrystallisation and Grain Growth 159

$\begin{array}{lc}\text { ChAPTER TEN } & 163\end{array}$

$\begin{array}{ll}\text { Discussions } & 163\end{array}$

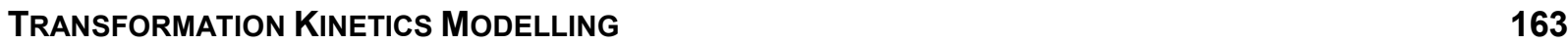

$\begin{array}{lll}10.1 & \text { Introduction } & 163\end{array}$

10.2 Modelling in Kinetics of Laves Phase Precipitation 163

10.2.1 Nucleation 163

$\begin{array}{lll}10.2 .2 & \text { Growth } & 164\end{array}$

10.2.3 Coarsening 165

10.2.4 Diffusion Coefficients 166

10.3 Parameters Required for Calculations 166

$\begin{array}{lll}10.4 & \text { Calculations } & 169\end{array}$

10.4.1 Volume Fraction and Particle Size $\quad 170$

$\begin{array}{lll}10.5 & \text { Summary } & 172\end{array}$

$\begin{array}{ll}\text { Chapter EleVen } & 173\end{array}$

$\begin{array}{ll}\text { CONCLUSIONS AND SUgGESTIONS FOR FURTHER WORK } & 173\end{array}$

$\begin{array}{lll}11.1 & \text { Conclusions } & 173\end{array}$ 
APPENDIX A 
Figure 1.1. Catalytic converters growth industry in South Africa [].

Figure 2.1. The effect of nickel and chromium content on the structure of the main stainless steels. Note in particular that $\mathrm{Ni}$ is a strong austenite former whereas $\mathrm{Cr}$ is a strong ferrite former [].

Figure 2.2. Effect of carbon and chromium contents on the structure of some of the main stainless steels. ELI is extra low interstitial steel [].

Figure 2.3. Fe-Cr equilibrium phase diagram [].

Figure 2.4. Shifting of the boundary line $(\alpha+\gamma) / \gamma$ in the Fe-Cr system through additions of $C+N$ [].

Figure 2.5. The effect of the grain size on the impact toughness for several $\mathrm{Fe}-25 \mathrm{Cr}$ ferritic stainless steels. Steel 59 and 68 are the alloy numbers [].

Figure 2.6. The effect of the interstitial content on the impact transition temperature for the Fe$18 \mathrm{Cr}-2 \mathrm{Mo}$ and $\mathrm{Fe}-25 \mathrm{Cr}$ steels with the grain sizes within the range 35 to $75 \mu \mathrm{m}$. The numbers given correspond to the alloy number [].

Figure 2.7. A schematic diagram of the grain boundary showing carbides in the chromiumdepleted zone near the grain boundaries.

Figure 2.8. Effect of niobium and titanium additions on the impact toughness of $18 \% \mathrm{Cr}-2 \% \mathrm{Mo}$ ferritic stainless steels [].

Figure 2.9. Zener's model for cleavage fracture.

Figure 2.10. Stroh's model for cleavage fracture.

Figure 2.11. Cottrell's model for cleavage fracture.

Figure 2.12. Smith's model for cleavage fracture.

Figure 2.13. Automobile exhaust system components.

Figure 2.14. Effect of alloying element additions on the $0.2 \%$ proof strength at $900{ }^{\circ} \mathrm{C}$ of a $13 \%$ Cr ferritic steel [].

Figure 2.15. The solvus temperatures of the precipitates found in stabilised ferritic stainless steels [].

Figure 2.16. Schematic flow diagram showing the Calphad approach used to obtain a thermodynamic description of a multicomponent system.

Figure 2.17. The three polytypes of the Laves phase structure in a hexagonal setting.

Figure 3.1 The free energy change associated with the formation of a stable nucleus with the radius $r$.

Figure 3.2. The ratio of the free energy required to form a nucleus on various types of grain boundary sites to that required to form a nucleus in the grain matrix, is plotted as a function of the contact angle parameter $\cos \theta$. 
Figure 3.3. Different possibilities of the precipitate's interface on grain boundaries.

Figure 3.4. Illustration of the variation of the function $f(c / a)$ of an incoherent nucleus with its shape.

Figure 3.5. Fully coherent precipitates, with no broken inter-atom bonds and with $\delta=0$. The interface is indicated by the circle.

Figure 3.6. Coherent precipitate with different lattice parameters only in the vertical direction. The volume influenced by the lattice misfit, $\varepsilon$ is marked by the dotted line.

Figure 3.7. The solute concentration profile during diffusion - controlled growth of $\beta$ from $\alpha$. $c^{\alpha \beta}$ and $c^{\beta \alpha}$ are concentrations at the interface $\alpha / \beta$ in the matrix $\alpha$ and the precipitate $\beta$, respectively.

Figure 3.8. A schematic isothermal section through the Fe-C-M phase diagram, showing the ferrite matrix $\alpha$ and alloy carbide $\beta$ fields. The alloy composition is plotted as point a [4].

Figure 3.9. Distribution of the solute when $(\mathrm{a})$ both $(\beta)$ and $(\gamma)$ are precipitating, and (b) where the precipitation of $(\beta)$ has been completed. Note that $\overline{c^{\prime}}$ is the instantaneous solute concentration in the matrix $(\alpha)[99]$.

Figure 3.10. The kinetics of the precipitation sequence in $9 \mathrm{Cr}-0.8 \mathrm{Nb}$ ferritic stainless steel [101].

Figure 4.1. Experimental plan.

Figure 4.2. Embrittlement through reheating to determine the effect of the Laves phase reprecipitation on the DBTT and upper shelf energy of steel A.

Figure 4.3. Embrittlement through cooling to determine the effect of the Laves phase reprecipitation on the Charpy impact toughness.

Figure 4.4. The furnace used for the precipitation kinetic study. (A) tube furnace; (B) temperature controller; (d) data logger; (D) type k thermocouple; $(E)$ recording computer.

Figure 4.5. The temperature gradient of the Charpy impact specimen inside the furnace.

Figure 4.6. Schematic diagram of the subsize tensile test specimen.

Figure 4.7. The XRD powder pattern of the phases that were expected to be present in type 441 stainless steel as generated using a PowderCell software.

Figure 4.8. The XRD powder pattern showing the peak's positions of the carbide and nitrides of titanium and niobium. Notice the position of the $(\mathrm{Ti}, \mathrm{Nb})(\mathrm{C}, \mathrm{N})$.

Figure 4.9. A typical XRD scan of the precipitate's residue from Steel A showing the presence of the Laves phase peaks (indicated by the lines in the top figure). The remaining peaks are the carbides and nitrides, indicated by $(*)$. Note the good residual difference between the calculated and the measured spectrum as is shown by the spectrum below.

Figure 4.10. The single crystal electron diffraction pattern

Figure 5.1. Thermo-Calc $®$ calculation of the isopleth diagram for type 441 stainless steel with a constant amount of alloying elements and 0 to $0.5 \mathrm{wt} . \%$ of carbon. Below any line, these represents the stable region for the phase. 
Figure 5.2. Thermo-Calc® calculation of the isopleth diagram for the high Mo-containing type 444 ferritic stainless steel $E$ with a constant amount of alloying elements and 0 to $0.5 \mathrm{wt} . \%$ of carbon.

Figure 5.3. The property diagram that shows the dependence of phase proportion on temperature; (a) mole fraction of stable phase and (b) weight fraction of stable phase.

Figure 5.4. Thermo-calc ${ }^{\circledR}$ plots of weight fraction of the stable phases as a function of the temperature in the Steel A with composition $0.444 \mathrm{Nb}-0.153 \mathrm{Ti}$; (a) Laves phase and (b) $(\mathrm{Ti}, \mathrm{Nb})(\mathrm{CN})$.

Figure 5.5. Thermo-calc® plots of weight fraction of the stable phases as a function of the temperature in the Steel B with composition $0.445 \mathrm{Nb}-0.149 \mathrm{Ti}$; (a) Laves phase and (b) $(\mathrm{Ti}, \mathrm{Nb})(\mathrm{CN}))$.

Figure 5.6. Thermo-calc® plots of weight fraction of the stable phases as a function of the temperature in the Steel $\mathrm{C}$ with composition $0.36 \mathrm{Nb}-0.171 \mathrm{Ti}$; (a) Laves phase and (b) $(\mathrm{Ti}, \mathrm{Nb})(\mathrm{C}, \mathrm{N})$.

Figure 5.7. Thermo-calc $®$ plots of weight fraction of the stable phases as a function of the temperature in the Steel $\mathrm{D}$ with composition $0.36 \mathrm{Nb}-0.171 \mathrm{Ti}-0.54 \mathrm{Mo}$; (a) Laves phase and $(\mathrm{b})(\mathrm{Ti}, \mathrm{Nb})(\mathrm{C}, \mathrm{N})$.

Figure 5.8. Thermo-calc $®$ plots of the weight fraction of the stable phases as a function of the temperature in the Steel $\mathrm{E}$ with composition $0.251 \mathrm{Nb}-0.106 \mathrm{Ti}-1.942 \mathrm{Mo}$; (a) Laves phase and $(\mathrm{b})(\mathrm{Ti}, \mathrm{Nb})(\mathrm{C}, \mathrm{N})$.

Figure 5.9. The normalised chemical composition of the Laves phase in Steel A: (a) is the mole fraction and $(b)$ is the weight fraction of a component in the phase.

Figure 5.10. The normalised chemical composition of the Laves phase in Steel B: (a) is mole fraction and (b) is a weight fraction of a component in a phase.

Figure 5.11. The normalised chemical composition of the Laves phase in Steel C: (a) is the mole fraction and (b) is the weight fraction of a component in the phase.

Figure 5.12. The normalised chemical composition of the Laves phase in Steel D: (a) is the mole fraction and (b) is the weight fraction of the component in the Laves phase.

Figure 5.13. The normalised chemical composition of the Laves phase in Steel E: (a) is the mole fraction and (b) is the weight fraction of a component in the Laves phase.

Figure 5.14. The free energy change $\Delta G$ for the precipitation reaction of Laves phase in ferrite with temperature for : (a) Steel A; (b) Steel B; (c) Steel C; (d) Steel D and (e) Steel E, calculated using Thermo-Calc $®$, $(G=\mathrm{J} / \mathrm{mol})$.

Figure 6.1. Micrographs from Steel $A$ in the as received hot rolled condition, showing the grain structure. (a) optical microscopy image and (b) SEM images. Note the large difference in magnification with figure (a) showing the "particle decorated" grain structure while figure (b) shows primarily the "particle decorated" subgrain structure.

Figure 6.2. Micrographs of the as received hot rolled Steel A showing its grain structure. (a) An optical microscopy image and (b) a SEM image.

Figure 6.3. SEM - EDS micrograph showing a precipitate consisting of a central cubic core of a mainly titanium containing particle surrounded by a cluster of niobium precipitates. 
Figure 6.4. Transmission electron micrographs of particles from extraction replicas and their analyses by electron diffraction and EDS of the as-received hot rolled Steel A showing different particle morphologies.

Figure 6.5. A typical XRD scan of the precipitate residue after electrolytic extraction from Steel A, i.e. the as received material, showing the presence of the Laves phase peaks (indicated by the lines in the top figure). The remaining peaks are the carbides and nitrides, indicated by $(*)$ and the $\alpha-$ Fe matrix, indicated by (*). Note the good residual difference between the calculated and the measured spectrum as is shown by the spectrum below.

Figure 6.6. Optical micrographs of the specimens from Steel A after annealing at different temperatures for 30 minutes followed by water quenching (In comparing the microstructures, note the differences in magnifications).

Figure 6.7. SEM micrographs of Steel A showing the effect of annealing temperature on the morphology of the second phase.

Figure 6.8. TEM micrographs from Steel A showing the presence of the fine Laves phase precipitates on the subgrain boundaries of the specimens that were annealed at the shown different temperatures for 1 hour and then water quenched.

Figure 6.9. Thin foil electron transmission micrographs from steel $\mathrm{A}$, annealed at $700{ }^{\circ} \mathrm{C}$ for 1 hour and then water quenched. The micrographs show (a) the nucleation of the Laves phase precipitates on grain boundaries and dislocations and (b) some fine matrix precipitates surrounded by a strain halo as well as dislocation nucleated precipitates.

Figure 6.10. Effect of annealing temperature on the room temperature Charpy impact energy of the as hot rolled and annealed AISI 441 stainless Steel A. The samples were annealed for 30 minutes and then water quenched.

Figure 6.11. Examples of the Charpy fracture surfaces at different magnifications of steel A (a \& b) from the as received specimen; (c \& d) after annealing at $850{ }^{\circ} \mathrm{C}$; and (e \& f) after annealing at $900^{\circ} \mathrm{C}$.

Figure 6.12. Effect of annealing temperature above $850{ }^{\circ} \mathrm{C}$ on the grain size and Vickers hardness for the AISI type 441 ferritic stainless Steel A.

Figure 6.13. TEM micrograph showing the presence of a dislocation substructure and some fine Laves precipitates in the as received hot rolled specimen of Steel A, indicating a lack of full dynamic recrystallisation during the last stage of hot rolling.

Figure 6.14. Effect of annealing temperature at $850{ }^{\circ} \mathrm{C}$ and above on the tensile strength and elongation of the 441 stainless steel $A$.

Figure 6.15. Charpy impact energy of the 441 ferritic stainless steel A as a function of the test temperature from specimens that were annealed at four different temperatures, both within and outside the Lave phase formation region.

Figure 6.16. Effect of linear cooling rate in ${ }^{\circ} \mathrm{C} / \mathrm{s}$ on the room temperature impact toughness of the specimens from Steel $A$ that were cooled at linear cooling rates from $850{ }^{\circ} \mathrm{C}$ and 950 ${ }^{\circ} \mathrm{C}$, respectively.

Figure 6.17. TEM micrographs of the samples of Steel A that were solution annealed at $850{ }^{\circ} \mathrm{C}$ and $950{ }^{\circ} \mathrm{C}$ for $5 \mathrm{~min}$ then cooled at $60^{\circ} \mathrm{C} / \mathrm{sec}$. (a \& b) solution treated at $850{ }^{\circ} \mathrm{C}$; (c \& d) solution treated at $950{ }^{\circ} \mathrm{C}$. Note the differences in the microstructures from both samples. 
Figure 6.18. TEM micrographs of the samples from Steel $A$ after being cooled at $1{ }^{\circ} \mathrm{C} / \mathrm{sec}$ from: (a) solution annealed at $850{ }^{\circ} \mathrm{C}$ and (b) $950{ }^{\circ} \mathrm{C}$ for 5 min before cooling.

Figure 6.19. Effect of the cooling rate on the volume fraction of the Laves phase in Steel A after cooling at different rates from annealing at $850^{\circ} \mathrm{C}$.

Figure 6.20. Charpy impact energy of Steel $A$ as a function of the test temperature of specimens first solution annealed at $950^{\circ} \mathrm{C}$ and then re-annealed at different temperatures.

Figure 6.21. Optical microscopy micrographs showing microstructural evolution in Steel A during re - heating treatments after an original solution treatment at $950^{\circ} \mathrm{C}$.

Figure 6.22. Effect of the Laves phase re-precipitation in Steel A on the hardness of the material during embrittlement treatment after an original solution treatment at $950^{\circ} \mathrm{C}$.

Figure 7.1. Effect of annealing treatment on the Laves phase's \% volume fraction, grain size and the Charpy impact toughness of the 441 ferritic stainless steel, Steel B.

Figure 7.2. Effect of the Laves phase precipitation kinetics on the Charpy impact toughness of Steel B.

Figure 7.3. Optical micrographs of the specimens from steel $B$ in the (a) as received plant hot rolled condition and (b) to (d) after being annealed at different temperatures from 850 to $950^{\circ} \mathrm{C}$ for 30 minutes followed by water quenching.

Figure 7.4. Effect of annealing temperature on the room temperature Charpy impact energy of the laboratory hot rolled materials. The samples were annealed for 30 minutes at different temperatures and then water quenched: Steel C (Nb-Ti alloy); Steel D (Nb-TiMo alloy) and Steel E (Type 444 alloy).

Figure 7.5. The microstructure of the laboratory hot-rolled experimental steels, showing different grain size distributions if compared to those of the commercial Steels A and B: (a) Steel C; (c) Steel D; and (d) Steel E.

Figure 8.1. The Laves phase volume fraction - temperature/time curves during isothermal annealing in the temperature range $600{ }^{\circ} \mathrm{C}$ to $850^{\circ} \mathrm{C}$.

Figure 8.2. The Laves phase transformation curves according to the Johnson-Mehl-AvramiKolmogorov (JMAK) type of equation.

Figure 8.3 A time - temperature - precipitation (TTP) diagram for the Laves phase formation in Steel A.

Figure 8.4. Effect of the grain size on the Laves phase kinetics transformation in Steel A. The specimens were annealed first at 850 and $950^{\circ} \mathrm{C}$ respectively to set different grain sizes and were then annealed both at $750^{\circ} \mathrm{C}$ for different annealing periods.

Figure 8.5. Effect of the steel's composition on the Laves phase transformation kinetics. The specimens from these steels were all annealed at $750^{\circ} \mathrm{C}$ for different annealing periods.

Figure 8.6. TEM micrographs of the specimen of Steel $A$ annealed at $600{ }^{\circ} \mathrm{C}$; (a) a low magnification micrograph shows coarse grain boundary Laves phase precipitates, and (b) the same area but at a high magnification, showing Laves phase precipitates nucleated on subgrain boundaries and dislocations.

Figure 8.7. TEM micrographs of the specimen of Steel A annealed at $750{ }^{\circ} \mathrm{C}$; (a) a low magnification micrograph showing grain and subgrain boundary Laves phase 
precipitates, and (b) at a high magnification, showing Laves phase precipitates nucleated on the subgrain boundaries.

Figure 8.8. TEM micrographs of the specimen annealed at $750{ }^{\circ} \mathrm{C}$; (a) at a low magnification, showing grain boundary Laves phase precipitates, and (b) at a higher magnification showing Laves phase precipitates nucleated on the subgrain boundaries.

Figure 8.9. Transmission electron micrographs and corresponding selected area diffraction (SAD) pattern from Steel A annealed at $600^{\circ} \mathrm{C}$.

Figure 8.10. Transmission electron micrographs and corresponding selected area diffraction (SAD) pattern from Steel A annealed at $750^{\circ} \mathrm{C}$.

Figure 8.11. Transmission electron micrographs and corresponding selected area diffraction (SAD) pattern from Steel $A$ annealed at $800^{\circ} \mathrm{C}$.

Figure 9.1. TEM micrograph shows the presence of the $\mathrm{M}_{6} \mathrm{C}$ or $\left(\mathrm{Fe}_{3} \mathrm{Nb}_{3} \mathrm{C}\right)$ type carbide in the subgrain structure from Steel $\mathrm{A}$. Note that the specimen was annealed at $700{ }^{\circ} \mathrm{C}$ for 30 minutes and other fine particles were determined to be $\mathrm{Fe}_{2} \mathrm{Nb}$ Laves phase particles.

Figure 9.2. Comparison between experimental and Thermo-Calc $®$ calculated weight fractions of Laves phase in Steel A. The points and dotted line represent the experimental results while the full line is as predicted by Thermo-Calc $®$ for this steel.

Figure 9.3. The effect of grain size on the yield strength of Steel A.

Figure 9.4. A room temperature tensile test of the specimen of Steel A that was annealed at 850 ${ }^{\circ} \mathrm{C}$ for 30 minutes and then water quenched.

Figure 9.5. High resolution field emission scanning microscope image showing the cracking of $(\mathrm{Ti}, \mathrm{Nb})(\mathrm{C}, \mathrm{N})$ particles after impact testing the specimen at room temperature. This specimen of Steel $A$ was annealed at $850^{\circ} \mathrm{C}$ followed by quenching in water.

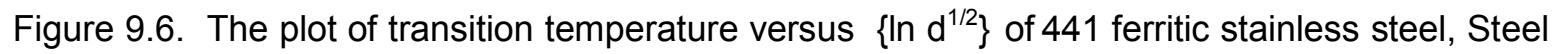
A.

Figure 9.7. Effect of annealing temperature above $850{ }^{\circ} \mathrm{C}$ on the grain size for the AISI type 441 stainless steel, Steel A.

Figure 9.8. TEM micrographs of the microstructures of the specimens from Steel $A$ that were annealed at (a) $850^{\circ} \mathrm{C}$ and (b) $900^{\circ} \mathrm{C}$. Note that with the specimen that was annealed at $900{ }^{\circ} \mathrm{C}$, there were no grain boundary Laves phase precipitates.

Figure 10.1. The relationship between $\ln x_{N b}^{\alpha \beta}$ and $T^{-1}$ for AISI type 441 ferritic stainless steel.

Figure 10.2. Comparison between the experimental data and calculated isothermal transformation curves for the Laves phase's precipitation at $700{ }^{\circ} \mathrm{C}$ in the AISI type 441 ferritic stainless, with $N_{o}=4.3 \times 10^{14} \mathrm{~m}^{-3}$ and $\gamma=0.331 \mathrm{Jm}^{-2}$.

Figure 10.3. Comparison between the experimental data and calculated isothermal transformation curves for the Laves phase precipitation at $800{ }^{\circ} \mathrm{C}$ in the AISI type 441 ferritic stainless, with $N_{o}=2.9 \times 10^{13} \mathrm{~m}^{-3}$ and $\gamma=0.331 \mathrm{Jm}^{-2}$. 
$\alpha_{3} \quad$ is the three-dimensional parabolic rate constant

$\beta^{*} \quad$ atomic impingement rate

$\delta \quad$ volume misfit of the precipitate in the matrix

$\delta_{\text {disl }}$ effective diameter of dislocation

$\delta_{g b} \quad$ width of the grain boundary

$\gamma \quad$ interfacial surface energy per unit area associated with the interface of the two phases

$\gamma_{f} \quad$ effective surface energy of ferrite

$\gamma_{s} \quad$ surface energy of the exposed crack surface

$\gamma_{T} \quad$ true surface energy

$\sigma_{i} \quad$ friction stress

$\sigma_{y} \quad$ yield strength

$v \quad$ Poisson's ratio

$v^{\alpha} \quad$ lattice spacing of the matrix

$\nu^{\beta} \quad$ lattice spacing of the precipitate phase

$v_{b} \quad$ mobility rate

$\tau \quad$ incubation time

$\tau_{e} \quad$ effective shear stress

$\tau_{i} \quad$ lattice friction shear stress

$\tau_{N} \quad$ shear stress for crack nucleation

$\tau_{y} \quad$ yield shear stress

$v^{\beta} \quad$ molar volume of the phase $\beta$,

$\tau_{s} \quad$ shear stress

$\Phi$ extent of the reaction parameter

$\theta \quad$ contact angle

a mean atomic lattice distance of the matrix phase

b Burgers vector

$\bar{c} \quad$ average concentration of the solute in the matrix alone

$c_{\alpha} \quad$ equilibrium solute composition within the matrix $c_{r}^{\alpha \beta} \quad$ solute concentration in the $\alpha$ matrix that is in equilibrium with a spherical particle of $\beta$ and $r$ is the radius of curvature

$c^{\alpha \beta} \quad$ equilibrium solute concentration in the $\alpha$ matrix at which $r \rightarrow \infty$

$c^{\beta \alpha} \quad$ corresponding concentration in the $\beta$ which is in equilibrium with $\alpha$,

$c_{i} \quad$ mole fraction of species $i$

$c_{j} \quad$ mole fraction of species $j$

d grain size

$D$ diffusion coefficient of the rate controlling solute atoms in the matrix

$D_{\text {disl }}$ diffusion coefficient down a dislocation

$D_{g b} \quad$ diffusion coefficient along the grain boundary

E Young's elastic modulus

$f_{G B} \quad$ fraction of potential grain boundary sites filled by solute

$G_{m} \quad$ shear modulus of the matrix

$G_{r} \quad$ growth rate

$\Delta G$ molar free energy change of the precipitate reaction

$\Delta G_{v} \quad$ Gibbs chemical free energy released per unit volume of new phase

$\Delta G_{\varepsilon} \quad$ misfit strain energy per unit volume

$\Delta G^{*} \quad$ known as the activation energy

$G^{\circ} \quad$ Gibbs energy due to the mechanical mixing of the constituents of the phase

${ }^{i d} G_{\text {mix }}$ ideal mixing contribution

${ }^{x s} G_{\text {mix }}$ excess Gibbs energy of mix (the non-ideal mixing contribution)

$\Delta G_{\varepsilon} \quad$ strain energy

$G_{m}-H_{m}^{\text {SER }}$ Gibbs energy relative to a standard element reference state (SER)

$h \quad$ Planck constants

$H_{m}^{S E R} \quad$ enthalpy of the element in its stable state 
$k \quad$ Boltzman constant

$k_{y}^{s} \quad$ Hall - Petch constant for shear

$L_{g b} \quad$ length of grain boundary per unit volume

$L_{i, j}^{k} \quad$ binary interaction parameter between species $i$ and $j$

$M_{0} \quad$ intrinsic grain boundary mobility in pure material

$M_{T} \quad$ overall mobility due to intrinsic plus solute drag

$M_{B} \quad$ mobility in the presence of solute drag elements

$n \quad$ number of dislocations in the pileup

$\dot{N} \quad$ nucleation rate

$N^{\prime}$ number of dislocations that meet each particle

$N^{*} \quad$ concentration of critical - sized nuclei

$N_{c}$ density of the grain boundary corners

$N_{0} \quad$ initial number density of nucleation sites per unit volume

$p_{d} \quad$ driving force for the grain boundary mobility
$\Delta p_{p p t}$ retarding force exercised by particles on the grain boundary

$Q \quad$ activation energy for diffusion

$r^{*} \quad$ critical radius

$r_{0} \quad$ initial average particle radius

$R \quad$ gas constant

$S_{g b} \quad$ surface area of grain boundary per unit volume

$t$ time

$T$ absolute temperature

$V^{\prime} \quad$ instantaneous volume fractions of alloy precipitates

$v^{e q} \quad$ equilibrium volume fractions of alloy precipitates

$V^{\beta} \quad$ instantaneous fraction

$V^{\beta \alpha} \quad$ maximum fraction of a given phase

$V^{i \alpha} \quad$ maximum volume fraction of the $i^{\text {th }}$ phase

$X_{s} \quad$ atom fraction of solute in the bulk metal

$z$ coordinate normal to the interface with the value $z^{*}$ 